\title{
A MORADIA COMO FATOR DE PROMOÇÃO DO DIREITO À SAÚDE DE MORADORES DAS MARGENS DOS IGARAPÉS NA CIDADE DE MANAUS
}

\author{
HOUSING AS A FACTOR IN PROMOTING THE RIGHT TO HEALTH FOR RESIDENTS \\ OF THE BANKS OF THE IGARAPÉS IN THE CITY OF MANAUS
}

\section{Paulo Sérgio Lima dos Santos ${ }^{1}$ Ana Carla Pinheiro Freitas ${ }^{2}$}

\begin{abstract}
1 Doutorando em Direito Constitucional do Programa de Pós-Graduação em Direito na Universidade de Fortaleza em parceria institucional com o Centro de Ensino Superior do Amazonas. Mestre em Direito Constitucional pela Instituição Toledo de Ensino em parceria institucional com o Centro de Ensino Superior do Amazonas. Professor de Pós-Graduação e Graduação em Direito da Escola Superior Batista do Amazonas. Advogado Militante na área de Direito Público. E-mail: professor.advogado.paulolima@hotmail.com
\end{abstract}

\begin{abstract}
2 Pós-Doutorado em Direito pela UNIFOR. Doutorado em Direito pela Pontifícia Universidade Católica de São Paulo. Mestrado em Direito (Direito e Desenvolvimento) pela Universidade Federal do Ceará. Graduado em Direito e em Psicologia. Professora dos cursos de mestrado e doutorado na UNIFOR. E-mail: anacarla@unifor.br
\end{abstract}

RESUMO: O crescimento populacional e a instalação da Zona Franca de Manaus proporcionaram importantes consequências socioeconômicas a muitas famílias manauaras, como: precariedade do emprego, queda na renda e aumento dos níveis de pobreza, levando a grande vulnerabilidade social. Como resultado dessa vulnerabilidade, a moradia tornou-se um ativo ameaçado pelo ambiente socioeconômico. Assim, a pesquisa tem como objetivo desvendar as condições de moradias nos igarapés de Manaus e como as condições de saúde estão vinculas as condições de moradia, em relação às condições de saúde da população que ali vive e sua relação com a moradia, ambos, direitos inalienáveis garantidos constitucionalmente.

Palavras-Chave: Direito à moradia. Direito à saúde. Igarapés de Manaus

\begin{abstract}
Population growth and the setting up of the Manaus Free Trade Zone brought important socioeconomic consequences to many Manaus families, such as: precarious employment, falling income and increasing levels of poverty, leading to great social vulnerability. As a result of this vulnerability, housing has become an asset threatened by the socioeconomic environment. Thus, the research aims to unveil housing conditions in the streams of Manaus and how health conditions are linked to housing conditions, in relation to the health conditions of the population living there and their relationship with housing, both rights constitutionally guaranteed.
\end{abstract}

Keywords: Right to housing. Right to health. Igarapés of Manaus.

Sumário: Introdução - 1 A subjetividade do direito à moradia - 2 O Direito Fundamental à Saúde - 3 O processo de urbanização da cidade de Manaus - 4 As condições de saúde da população que vive às margens dos igarapés em Manaus - Considerações Finais - Referências

\section{INTRODUÇÃO}

Ter um lar é condição indispensável para sobreviver e se desenvolver como ser humano em termos de segurança, autonomia e independência. No entanto, a despeito da importância do tema, ainda são inexpressivos os esforços feitos para refletir sobre moradia no espaço teórico do Direito e, em especial, a sua relação com a garantia ao direito à saúde. $\mathrm{O}$ direito à moradia visa satisfazer a necessidade que cada pessoa tem de poder contar com um local adequado para morar.

É considerado como um direito inalienável ao indivíduo e é concebido como a proteção do ser humano e de sua família, atuando como plataforma para seu desenvolvimento e influenciando seu progresso individual e coletivo. Tem sido acatado como um direito composto, isto é, seu exercício é necessário para a 
realização de outros direitos, cuja finalidade não se esgota com um espaço para dormir ou estar, mas, ao contrário, sua violação afeta a manutenção de outros direitos humanos.

A violação do direito à moradia ameaça, por exemplo, o direito à integridade física e mental, como quando o indivíduo vive na impossibilidade de cobrir o pagamento de um aluguel; também viola o direito ao trabalho; coloca em risco o direito à saúde, à educação e ao livre desenvolvimento das pessoas, impossibilitandoas de praticar em espaços lotados sem condições mínimas de habitabilidade.

Esse cenário sugere reflexões sobre o direito à moradia como direito humano e constitucional e sua relação com o Direito à Saúde na cidade de Manaus, onde existe um contingente elevado de pessoas que vivem em situações de risco real quanto à sua saúde, por terem fixado residência às margens de igarapés que cortam a cidade. A finalidade é contribuir para a discussã o sobre as condições ideais que permitam a realização do exercício desse direito por todos os brasileiros, em especial os moradores da cidade de Manaus.

\section{A SUBJETIVIDADE DO DIREITO À MORADIA}

A questão do direito à moradia está intimamente relacionada à sua garantia e proteção como um direito subjetivo de natureza social e como um direito fundamental, partindo da premissa de que se pretende tornar efetivo o direito à moradia digna e, para esse fim, é preciso proceder, antes de qualquer coisa, o seu reconhecimento formal como um direito subjetivo e como um direito fundamental para, a partir de então, fazer emanar a efetiva proteção legal por meio dos dispositivos previstos para a proteção deste tipo de direitos, sem necessidade de posterior desenvolvimento legislativo.

Vale recordar, na visão de Bitencourt Neto (2010), que essa abordagem se enquadra em um contexto de crise que exige socialmente a necessidade de moradia digna e tendo em mente que, embora as políticas de habitação pública tenham sido tradicionalmente articuladas sobre a moradia protegida ou social, nos últimos anos, devido à falta de habitação "digna", elas também foram orientadas para a reabilitação de casas existentes, bem como para a reforma do mercado de arrendamento e outras formas de posse da habitação. No entanto, deve-se notar que tudo isso foi feito sem haver um critério mínimo de técnica legislativa coerente e sem uma política habitacional global que aborde todos esses aspectos.

De fato, para especificar uma política habitacional adequada, deve-se partir da consideração da moradia como um direito subjetivo, além de ser um direito fundamental, bem como do estudo do conteúdo próprio do direito protegido, do significado do adjetivo digno que acompanha a o substantivo moradia, sendo a moradia digna uma necessidade básica do indivíduo.

O reconhecimento da moradia como um direito é estabelecido a nível internacional de forma clara, como parte do conteúdo do direito subjetivo a um padrão de vida adequado, essencialmente na Declaração Universal dos Direitos Humanos (DUDH/1948, Art. 25), que proclama que "Toda pessoa tem direito a um padrão de vida adequado que garanta, assim como à sua família, saúde e bem-estar e, principalmente, alimentação, vestuário, moradia, assistência médica [...]”, assim como no Pacto Internacional dos Direitos Econômicos, Sociais e Culturais (PIDESC) homologado pelo Decreto Federal no 591 de 1992) que determina que

Os Estados Partes do presente Pacto reconhecem o direito de toda pessoa a um nível de vida adequando para si próprio e sua família, inclusive à alimentação, vestimenta e moradia adequadas, assim como a uma melhoria contínua de suas condições de vida. Os Estados Partes tomarão medidas apropriadas para assegurar a consecução desse direito, reconhecendo, nesse sentido, a importância essencial da cooperação internacional fundada no livre consentimento (PIDESC/1992, Art.11, 1).

O referido Pacto recomenda inclusive que os Estados Partes tomem medidas apropriadas para assegurar que o direito à moradia adequada tenha sua plena eficácia jurídica. O Comentário Geral n 4 do Comitê dos Direitos Econômicos, Sociais e Culturais (CDESC - BRASIL, 2013) sobre o direito à 
moradia adequada determina as condições específicas que constituem o caráter apropriado da habitação, desenvolvendo o conteúdo do Artigo 11.1 do PIDESC.

Nesse sentido, segundo Corrêa (2007), não só determina que o direito à moradia adequada seja para todos, interpretando a afirmação do PIDESC sobre "para si e sua família", pois não se pode impor nenhuma limitação em relação ao gênero, mas também que o conceito de "família" deve ser entendida em um sentido amplo e não literal da palavra.

Cardoso (1986), determina o objeto do direito, afirmando que o direito à moradia não se trata de o indivíduo ter um teto ou abrigo para si, mas sim o direito de viver em segurança, paz e dignidade em algum lugar, com o qual o conceito de moradia "adequada" permite entender os seguintes elementos: segurança jurídica da posse (incluindo proteção contra o despejo); disponibilidade de serviços, materiais, instalações e infraestruturas (incluindo acesso à água potável e serviços sanitários); habitabilidade (incluindo proteção contra frio, umidade, calor, chuva, vento e doenças); acessibilidade; local (um local adequado, longe de fontes de poluição e perto de serviços de saúde e escola) e adequação cultural.

No entanto, como afirma Dallari (2002), apesar do significativo reconhecimento legal concedido ao direito à moradia em nível nacional e internacional, ainda é possível afirmar que ele é débil e escassamente garantido no Brasil, o que contraria o que preconiza Nolasco (2008), para quem o direito à moradia não só proporciona um bem necessário em si, mas também depende da garantia do exerć́cio efetivo do direito à proteção contra a pobreza e a exclusão social, e que obriga os Estados Partes a tomar medidas de âmbito de planejamento global e coordenado para provocar o acesso efetivo ao emprego, habitação, formação, educação, cultura e assistência social e médica ao indivíduo que se encontrem ou corram o risco de estar em situação de exclusão social ou pobreza, assim como suas famílias.

A conexão entre moradia e proteção e efetividade dos direitos civis e políticos é clara (direito à vida, honra, privacidade, participação política e saúde), assim como o pressuposto indispensável para a efetivação e garantia de outros direitos sociais e econômicos e culturais, como: educação, trabalho e saúde (ALEXY, 2011).

Todos os direitos subjetivos implicam um dever legal correlativo e, portanto, um sujeito obrigado a tornar o direito efetivo. Nesse sentido, há uma relutância desde a configuração jurídica do direito, alegando sua impossibilidade de efetivá-lo em sentido absoluto. De qualquer forma, se trata de uma obrigação de meios, e não de resultados, que as autoridades públicas reconheçam, respeitem, protejam e promovam as medidas necessárias para garantir uma moradia decente e adequada a todos.

\section{O DIREITO FUNDAMENTAL À SAÚDE}

O termo saúde, dentro da expressão "direito à saúde" própria do discurso jurídico, sofre do mesmo inconveniente que caracteriza, à linguagem natural, sua imprecisão. A Organização Mundial da Saúde (OMS) define saúde como "não apenas como a ausência de doença, mas como a situação de perfeito bem-estar físico, mental e social” (SEGRE; FERRAZ, 1997, p. 539). Embora o direito à saúde não possa ser concebido como a manutenção a todo custo do estado referido pela OMS, esta afirmação obedece a razões estritamente factuais, já que nenhuma norma legal pode distorcer o curso inexorável da ocorrência natural. No entanto, deve-se notar que a qualidade de vida é um dos elementos essenciais do direito à saúde (ABREU, 2008).

A busca pela saúde é uma constante na história da humanidade que, desde os mais remotos tempos, dedica-se a encontrar curas para os seus males e a construção e evolução do conceito de saúde acompanha a trajetória de evolução dos homens e da sociedade, refletindo as conjunturas sociais, políticas, locais, filosóficas, culturais e religiosas da época. Vale lembrar que

Há, para cada período histórico e para cada lugar no mundo, um conceito de saúde próprio, demonstrando o seu caráter dinâmico e aberto e, por isso, reflexivo, na medida em que, em tempos de mercantilização de tudo, inclusive da saúde, é imprescindível retomar algumas premissas elementares que a definem e, quiçá, incentivar aos que com ela lidam (profissional, pessoal ou mesmo politicamente) 
dediquem-se a promovê-la, antes de tudo (ASENSI, 2012, p. 33).

Conforme aponta Bittar (2005, p. 103), nas primeiras civilizações, onde o objetivo maior dos povos era a sua própria sobrevivência, as doenças eram vistas como causas externas ao corpo, "resultado de forças alheias ao organismo que neste se introduzem por causa do pecado ou de maldição". A saúde, na linha oposta, traduzia uma recompensa pelo bom comportamento.

A Grécia antiga (século $\mathrm{V}$ a.C.) foi quem promoveu a grande ruptura na concepção mágico-religiosa dos fenômenos de doença e saúde que, por meio de uma perspectiva racional, passou a explicá-los por meio de causas naturais, ainda que coexistisse um imaginário religioso advindo da prática de cultuar os deuses como Hygieia, a deusa da saúde, e Panacea, a deusa da cura. Surge, nesse momento, o grande nome da medicina - Hipócrates (FLEURY et al, 2007).

Com o desenvolvimento da anatomia patológica durante a modernidade - após o retrocesso ocorrido na Idade Média, onde a saúde, sob forte influência da Igreja Católica, passou a ser vista, novamente, como uma graça divina e a doença como a purificação de algum pecado - uma nova concepção de saúde entra em cena: a da ausência de doença. De fato, a partir da prática de dissecação de cadáveres se passa a compreender que a doença está no corpo e não fora dele, como até então ocorria, de modo que, ao transformar a doença em patologia, a saúde passa a ser entendida como seu oposto lógico, ou seja, a ausência de doença. Nas palavras de Gazola (2008, p. 95), a saúde seria "o silêncio dos órgãos".

Não obstante os avanços, a visão sobre saúde/doença ainda era apenas orgânica. O grande marcoteórico do conceito de saúde vem no final da primeira metade do século XX, quando a OMS, em 1946, ofereceu a antes mencionada definição, alargando a definição de saúde, até então restrita aos aspectos preventivos e curativos, para considerá-la também uma conquista social e cultural, introduzindo a ideia de promoção da saúde pelo poder público (FLEURY et al, 2007).

Barroso (2013) afirma que a abrangência de seu conteúdo instigou a elaboração de diversas críticas, como a impossibilidade de conceituar o que seria estado de bem-estar, os limites econômicos das nações para atenderem o pretendido estado de completo bem-estar dos cidadãos, tornando-se comum o fato de ser considerado um conceito inaplicável e utópico.

Contudo, partilha-se da observação que fez Asensi (2012), segundo o qual os trabalhos de crítica dessa conceituação terminam concluindo que, embora o estado de completo bem-estar não exista, a saúde dever ser entendida como a busca constante de tal estado, uma vez que qualquer redução na definição do objeto o deformará irremediavelmente. Assevera, ainda, que uma das consequências da definição ampliada de saúde é a compreensão de que ninguém pode ser individualmente inteira e exclusivamente responsável por sua saúde. Conforme Bittar (2005), em 1978, surpreendendo ao ampliar seus objetivos, a OMS promoveu a Conferência Internacional de Assistência Primária à Saúde, realizada na cidade de Alma-Ata (atual Cazaquistão), como resultado de uma crescente demanda por maior desenvolvimento social.

$\mathrm{Na}$ ocasião, destacou os aspectos sociais da questão da saúde, enfatizando as enormes desigualdades nas condições de saúde entre países desenvolvidos e subdesenvolvidos; bem como a responsabilidade governamental na provisão da saúde, as quais deveriam incluir, pelo menos, educação em saúde, nutrição adequada, saneamento básico, cuidados materno-infantis, planejamento familiar, imunizações, prevenção e controle de doenças endêmicas e provisão de medicamentos essenciais, em consonância com a bandeira de luta erguida pela Reforma Sanitária pré-constituinte e cuja vitória pode ser traduzida a partir do reconhecimento, pela Constituição da República Federativa do Brasil (CRFB), de 1988, da saúde como um direito de cidadania.

Nesse sentido, valiosa a contribuição de Sarlet (2001) a respeito da sua definição sobre dignidade humana, o qual, após advertir o leitor acerca da complexidade e, pois, dificuldade em conceituá-la, limitou o seu estudo a uma análise apenas parcial das dimensões que a envolvem, tendo assim concluído que

Tem-se por dignidade humana a qualidade intrínseca e distintiva reconhecida em cada ser humano que o faz merecedor do mesmo respeito e consideração por parte do Estado e da comunidade, implicando, neste sentido, um complexo de direitos e deveres fundamentais que assegurem a pessoa tanto contra 
todo e qualquer ato de cunho degradante e desumano, como venham a lhe garantir as condições existenciais mínimas para uma vida saudável, além de propiciar e promover sua participação ativa e corresponsável nos destinos da própria existência e da vida em comunhão com os demais seres humanos (SARLET, 2001, p. 97).

E, no que tange especificamente ao direito prestacional à saúde, este se reveste de singular fundamentalidade enquanto intrínseco à própria existência digna do homem. Vale dizer, ainda que beire o evidente, que sem a mínima realização do direito à saúde, os demais direitos restam materialmente esvaziados, na medida em que comprometida a sua fruição por aqueles que não possuem condições mínimas de saúde e qualidade de vida. Assim, a proposta da Lei Fundamental sobre respeito e proteção da dignidade humana não se limita a um direito de defesa contra ingerências e ameaças à liberdade pessoal por parte do Estado, mas também vincula, positivamente, os órgãos estatais a que assegurem a cada pessoa uma vida humanamente digna e isso passa, necessariamente, pela realização plena do direito à saúde.

Em verdade, a condição que assume o direito prestacional à saúde diante de todos os demais direitos - também essenciais, como educação e moradia, bem como frente à própria noção de democracia, soberania e cidadania, pilares de um país orientado por valores morais como a dignidade humana - revela-se prioritária, a ser primeiramente atendida, na medida em que o povo que não usufrui de mínimas condições de vida, não conta com a dignidade humana necessária para que tais predicados se realizem.

\section{O PROCESSO DE URBANIZAÇÃO DA CIDADE DE MANAUS}

A cidade de Manaus está localizada na região amazônica, no estado brasileiro do Amazonas. Até 1960 localizava-se a 18 milhas da foz do rio Negro. Atualmente os limites da cidade passam pela foz do rio Negro e prolongam-se até o rio Amazonas, já que seu limite é o rio Puraquequara, que deságua no rio Amazonas (OLIVEIRA e SCHOR, 2008). Manaus foi fundada em uma data incerta no ano de 1669, com a construção do forte de São José do Rio Negro, localizado no atual centro da cidade, em uma área chamada Largo da Trincheira (PINTO, 1992).

A fundação do forte faz parte da estratégia geopolítica da colônia portuguesa de demarcação de terras, na qual a implantação de fortes e missões foi estabelecida em todo o vale do Amazonas. A implantação do forte que deu origem à cidade de Manaus foi a mais expressiva dessa estratégia (OLIVEIRA e SCHOR, 2008). O centro iniciou seu processo de urbanização desde $1791 \mathrm{com}$ a transferência da sede da capitania de São José da Barra do Rio Negro (ex-Mariuá, atual município de Barcelos) para a ilha de São Vicente, que foi renomeada Lugar da Barra (NUNES e HATOUM, 2005).

Segundo Mesquita (2006), Manaus foi embelezada e urbanizada como a aspiração de uma ávida elite em demonstrar seu status. Embora essas aspirações tenham sido registradas em diferentes documentos durante a segunda metade do século XIX, é somente após a criação da República e graças aos excessos econômicos da borracha que esses projetos foram materializados no final do século XIX. Na primeira década do século XX, a cidade de Manaus se apresentava com características modernas e embelezadas, de acordo com o progresso da época.

Durante a última década do século XIX, durante o governo de Eduardo Ribeiro (1892-1896), teve início o Plano de Embelezamento da Cidade de Manaus, projeto que foi continuado nos dois sucessivos governos e que envolveu obras na região central da cidade, nivelamento de ruas, construção de prédios, de pontes e ações de infraestrutura e serviços públicos de energia elétrica, água potável, saneamento, aterramento de igarapés, transporte coletivo e rede telefônica. De acordo com Mesquita (2006), eram símbolos que atribuíram à cidade de Manaus o status de um centro civilizado. Milhares de toneladas de látex passaram pela cidade para serem exportadas e, bens e pessoas circularam.

No final dos anos 1920, com a crise da Bolsa de Nova York, a economia brasileira voltada para o mercado de exportação entrou em crise. Essa crise afetou a economia do estado do Amazonas e, nos anos 1930, o declínio da borracha atinge seu pico. O período chamado "Batalha da Borracha", durante a Segunda 
Guerra Mundial, determinou um novo período na Amazônia devido ao bloqueio dos seringais asiáticos. Benchimol (1977, apud Oliveira e Schor, 2008) estima que nesse período cerca de 75.000 pessoas, provenientes do Nordeste, chegaram em sua maioria nos estados do Amazonas, Acre, Rondônia e Roraima.

Quando o conflito mundial termina, o interesse externo pela borracha cessa. Sua produção é agora direcionada para o abastecimento interno de indústrias de pneus em São Paulo. Devido, também, à diversificação da produção extrativista e da agricultura, especialmente com o cultivo de juta e guaraná, a crise do seringal não significou o colapso total. A década de 1940 corresponde à mudança do padrão de urbanização da sociedade brasileira (OLIVEIRA e SCHOR, 2008).

Fatores como a expansão, modernização e mecanização de grandes propriedades e a estagnação de algumas áreas geraram desemprego, luta pela terra e êxodo rural. Esse processo ocorreu de forma desigual nos territórios e as cidades que receberam maior investimento nas políticas foram aquelas localizadas na região concentradora da atividade industrial, reservando um papel subalterno para a Amazônia e, principalmente, para Manaus (OLIVEIRA e SCHOR, 2008).

Entre as décadas de 1950 e 1960, a Cidade Flutuante, localizada na frente da cidade de Manaus e estendendo-se até a foz do igarapé dos Educandos, tem seu maior crescimento. Era formada por um conjunto de casas de madeira construídas sobre troncos de árvores que os faziam flutuar nas águas do rio Negro e nos igarapés da cidade de Manaus. Esse tipo de arquitetura, diz Monteiro (1994), foi encontrado no interior, nas comunidades ribeirinhas.

Seu surgimento é explicado pelas precárias condições de vida e pela falta de moradia na cidade de Manaus, sendo uma alternativa de moradia mais barata do que em terra, já que a água não é constituída como propriedade privada. As casas da Cidade Flutuante eram construídas em toras de açacu, as paredes de madeira eram cobertas com palha, zinco ou alumínio (OLIVEIRA e SCHOR, 2008). Seus proprietários eram cearenses egressos dos seringais, no período de plena decadência (ANDRADE, 1984).

A Cidade Flutuante existiu até 1966, quando, em meio a uma política de integração nacional dos governos militares, foi implantada na cidade de Manaus uma Zona Franca, cujas metas de modernização e progresso da capital amazonense não incluíam a cidade flutuante, pelo contrário, passavam pela sua completa destruição (BARATA SOUZA, 2010).

Segundo Nunes e Hatoum (2005), as populações que habitavam os flutuantes foram transferidas para áreas mais distantes do centro e para conjuntos habitacionais construídos para essas populações, o que se constitui uma sutil expulsão dessas populações e desse modo de habitar a cidade.

No período após a implantação da Zona Franca de Manaus, a cidade cresceu em termos espaciais e demográficos. A expansão do tecido urbano foi em direção às áreas leste e norte da cidade. Por outro lado, inicia-se um intenso processo de ocupação e especulação imobiliária na zona oeste da cidade, Ponta Negra e Tarumã, onde morar em frente ao rio passa a ser sinônimo de status econômico e social. Por sua vez, algumas áreas da periferia ganham serviços urbanos, fazendo com que o centro perca sua exclusividade (OLIVEIRA e SCHOR, 2008).

\section{AS CONDIÇões DE SAÚdE DA POPULAÇÃo QUE VIVE ÀS MARGENS DOS IGARAPÉS EM MANAUS}

Tanto a Amazônia, de um modo geral, quanto o Estado do Amazonas, particularmente, tem sofrido nos últimos anos um acelerado êxodo do meio rural para as cidades. Esse fenômeno acontece em vista do surgimento de necessidades básicas, como educação, moradia e saúde ou apenas a esperança de viver melhor, com mais tranquilidade. Em Manaus, esse deslocamento teve início após a implementação, em 1967, da Zona Franca, quando a capital amazonense cresceu em um ritmo vertiginoso, chegando a quase 7\% ao ano. À guisa de comparação, Carvalho (2009) aponta que, nessa mesma época, o Brasil teve um crescimento da ordem de $3 \%$ ao ano.

Essa população que abandona o ambiente rural e chega para morar na capital começa a se encaixar entre 
os contingentes de menor poder aquisito da cidade, tornando-se, portanto, o contingente mais vulnerável sob os mais diversos aspectos, mas principalmente no que tange à saúde. Apesar dessa vulnerabilidade, o fato é que, por se aglomerarem em locais onde existe carência de recursos urbanos, enfrentando as piores situações, como falta de água, luz e saneamento, acabam não aparecendo nas pesquisas globais sobre tais condições de vida da população.

A Declaração das Nações Unidas sobre Direitos Humanos estipula que todos têm o direito a um padrão de vida adequado, que garanta sua saúde e bem-estar, e isso inclui a moradia. No entanto, em mais de uma ocasião o CDESC das Nações Unidas expressou mais sua preocupação em seu exame do Brasil. Entre muitos outros direitos básicos, criticou a fraca proteção do direito à moradia no país, observando particularmente que algumas medidas tomadas nos últimos anos acabaram por prejudicar o gozo do direito à moradia adequada, especialmente dos grupos mais desfavorecidos e vulneráveis (BRASIL, 2013).

Também criticou o Brasil pelo número insuficiente de moradias sociais e o alto preço das residências, especialmente pelo número significativo de famílias que não têm moradia adequada e pelo alto número de moradores de rua (BITTAR, 2005). Tradicionalmente, segundo Corrêa (2007), a habitação tem sido entendida como o espaço físico onde o indivíduo pode descansar, dormir, comer, ter atividades recreativas e realizar funções sociais e relacionais com a família em sua ampla concepção (amigos, conhecidos etc.). Deve ser, portanto, um espaço de recolhimento e privacidade.

No entanto, conforme estabelecido pela própria OMS (2019), quando essas condições não são atendidas ou são insuficientes, o direito à moradia não está sendo garantido e, assim, evita-se que a garantia ao direito à saúde seja efetivada. Assim, tanto a existência ou não de um lugar, as condições físicas do lar e seu ambiente físico, como o ambiente social do bairro podem afetar a saúde física, mental e relacional das pessoas.

Em Manaus, esta situação pode ser observada com clareza durante um passeio rápido pelas margens dos igarapés que cortam a cidade. De fato, um dos problemas capitais da cidade é a ocupação desenfreada nas áreas dos igarapés. A impressão imediata é a de que existe um núcleo urbano ilhado pela floresta virgem, voltado para a baía do Rio Negro e cortado por pequenos rios e igarapés, dando a certos bairros a imagem de uma Veneza tropicalizada e primitiva, lembrando cidades orientais pela desarrumação das habitações nas margens dos rios e pela precariedade que essas construções aparentam - palafitas e casas de madeira cobertas de palha, atingíveis por ruas ou caminhos ou, durante as cheias, por barcos e canoas (CORREA, 2007).

Muitos destes igarapés recebem esgoto, tanto de origem industrial quanto doméstica, que causam forte degradação nos percursos dos igarapés. E em alguns pontos as palafitas foram substituídas pelos conjuntos residenciais do Programa de Saneamento Ambiental dos Igarapés Manaus (PROSAMIM). De fato, segundo o Conselho Nacional de Meio Ambiente (CONAMA, 2019), as águas dos igarapés de Manaus se encontram bastante alteradas pela ação do homem, apresentando qualidade inferior à estabelecida como "Classe 4", a pior qualidade de águas definida; ou seja, as águas estão inutilizadas no que concerne à potabilidade, caracterizando-se, atualmente, como um mero canal de drenagem do esgoto e água pluviais.

No local existem moradores que ali já vivem há mais de 30 anos, saídas de sua cidade natal em busca de melhores condições de vida. De fato, há 30 anos as condições já foram melhores, quando as águas dos Igarapés ainda eram limpas e cristalinas e serviam tanto como fonte de alimentos quanto de divertimento para os mais jovens, que nadavam e brincavam o tempo todo nas águas rasas. No entanto, atualmente as pessoas enfrentam muitos obstáculos à própria saúde e de toda a família (muitas formadas por vários membros, inclusive crianças, que moram em casas montadas sobre palafitas e divididas em várias partes, uma para cada família), pois todos são atingidos pela época das cheias, que é quando as águas invadem as casas dos moradores e trazem aflição e doenças.

Para fugir das enchentes e dos problemas que chegam juntamente com elas, as pessoas constroem "marombas", que nada mais são do que pontes de madeira que ligam as casas umas às outras e à terra firme, mas quase sempre ainda têm que lidar com a presença de ratos, aranhas e até cobras que entram pelos vãos das paredes de madeira. O medo de ser mordido e contrair doenças é sempre uma constante entre estas pessoas. 
De fato, segundo Scliar (2007), as ligações entre habitação e problemas de saúde (patologias, deficiências, síndromes, distúrbios, envenenamentos e alergias) são evidentes quando se refere a pessoas em situação de exclusão sócio-residencial: pessoas desabrigadas, dormindo na rua em casas improvisadas ou em condições precárias, famílias forçadas a viver em moradias precárias, casas insalubres, deficientes, úmidas e muito degradadas. Como exemplo, fica claro que pessoas que não conseguem manter uma temperatura adequada em sua casa podem ter doenças cardiovasculares e respiratórias. Também pragas e insetos ou outros animais relacionados a reações alérgicas e várias doenças infecciosas.

Saule Júnior (2004) afirma que o reconhecimento do direito à moradia como um direito constitucional está ligado à sua consideração como uma necessidade básica essencial para viver com dignidade e segurança, para desenvolver livremente a própria personalidade e participar, mesmo nos assuntos públicos. Sua violação põe em questão a integridade física e mental das pessoas, sua vida privada e familiar e sua liberdade de residência. A ausência deste direito afeta a saúde e o meio ambiente, tanto individual quanto coletivamente, e prejudica o direito ao trabalho, à educação e até à participação. Não é estranho, portanto, que a garantia do direito à moradia pareça estar cada vez mais ligada ao direito mais amplo a um ambiente urbano inclusivo, sustentável e democraticamente gerenciado ou, se preferir, ao direito à cidade.

De acordo com Asensi (2012), as infecções transmitidas pelo ar, devido a bactérias e vírus são comuns no ser humano, seja pela disseminação de micro-organismos que passam de pessoa a pessoa pelo ar, pelo contato direto ou por ingestão. O homem passa até 24 horas por dia em sua residência, sendo assim as más condições da casa, especialmente quando acompanhadas de má nutrição e falta de higiene, tendem a causar infecções respiratórias, assim como o mofo ou a falta de ventilação.

Também é importante enfatizar o estresse causado pela insatisfação em relação às condições de alojamento e da falta de privacidade, entre outros fatores, que podem causar problemas de saúde mental, tais como percepção de bem-estar, ansiedade, depressão, insônia, ou problemas comportamental e acadêmico na infância. Isso acontece em vista do estigma do qual sofrem as pessoas em situação de exclusão, o que intensifica ainda mais o sofrimento. $\mathrm{O}$ alto custo da habitação ou a inserção em uma espiral de dívida, como é frequente acontecer no meio destas famílias vulneráveis, também, pode levar ao estresse psicológico grave, prejudicar outras necessidades básicas, como alimentos ou causar instabilidade ou grande superlotação residencial.

No contexto atual, em que o direito à moradia se tornou uma utopia, a saúde se torna turva. Considerando-se os determinantes socioeconômicos da saúde, percebe-se claramente que a moradia é um elemento fundamental para o desenvolvimento de uma vida saudável. Pode-se afirmar que as dificuldades próprias do local, inclusive no que tange à mobilidade dos habitantes mais velhos ou doentes das zonas próximas a igarapés, devido à topologia do local, afetam o cotidiano de todos os seus habitantes. Essas dificuldades poderiam ser resolvidas se uma via de acesso adequada, à área fosse construída.

Vale ressaltar que os moradores destas zonas de risco precisam constantemente contar com a ajuda de seus vizinhos durante os momentos de angústia causados seja pelos desastres (inundações e deslizamentos de terra). A partir dessa perspectiva, percebe-se que os problemas acima mencionados tendem a se agravar - especialmente nas cidades - já que, como afirma Gazola (2008), o homem das cidades modernas alcançou um grau de anonimato, atomização social e isolamento espiritual sem precedentes na história humana. Para este autor, a vida metropolitana está sendo destruída psicologicamente, economicamente e biologicamente.

Para Saule Júnior (2004), a vida, a saúde física e mental de todas as sociedades depende de certas estruturas psicológicas, que são infinitamente preciosas e altamente vulneráveis: coesão social, cooperação, respeito mútuo e, acima de tudo, respeito por si mesmo, coragem diante da adversidade e da capacidade de lidar com a privação, tudo isso e muito mais se desintegra e desaparece quando essas estruturas psicológicas estão muito prejudicadas

Para entender a relação entre saúde e moradia, e também os problemas decorrentes de sua falta, o olhar tem que ser amplo, tanto do conceito de saúde quanto do conceito de lar. A partir da abordagem adotada neste artigo, não é possível ignorar o relacional nem negligenciar a vizinhança. É importante considerar o emocional e não esquecer a segurança da posse. Nem a patologia pode ser negligenciada, assim como 
a qualidade da habitação não deve ser ignorada. Somente a partir de uma abordagem multidimensional para situações de vulnerabilidade residencial será possível realmente estabelecer as propostas que deverão ser realizadas no que tange à moradia. Será desta perspectiva que surgirá a capacidade de determinar se, finalmente e em cada caso específico, se está lidando com um fator de risco ou um fator de proteção.

\section{CONSIDERAÇÕES FINAIS}

O risco e a incerteza enfrentados por indivíduos e famílias no Brasil, particularmente na cidade de Manaus, em termos de redução de seus ativos diante de diversas eventualidades ou do não aproveitamento de oportunidades para melhorar o bem-estar pessoal ou familiar, podem estar condicionados por diferentes situações. Entre esses fatores, destacam-se aspectos como: fragilidade da economia familiar frente a mudanças de renda, precarização e instabilidade no emprego e consequente inacessibilidade da previdência social, diminuição da capacidade de suportar catástrofes eventuais, a insegurança do ambiente espacial cotidiano que pode trazer grandes riscos a saúde, entre outros.

Esses aspectos, que têm a ver com emprego, renda, tipos de família e sua composição, envolvem a localização de indivíduos e famílias em situação de risco diante de eventos que conspiram contra sua capacidade de subsistência dentro de um cenário de pobreza, ou, no caso deste estudo, quando ativos, como a moradia, são o fator preponderante de ameaça à segurança, à habitabilidade e à saúde. Tais aspectos e riscos podem ser considerados sob a abordagem de vulnerabilidade social.

De fato, as populações que moram nas residências de palafitas nos igarapés de Manaus vivem em situação de permanente risco social, quer pelas condições subumanas da vida, quer pela constante ameaça que situações adversas, como a prostituição, o tráfico de drogas, os desastres naturais e os poucos recursos direcionados á saúde propriamente dita. Isso faz com que estas populações se encontrem à mercê dos riscos de desabamento das residências, das doenças de veiculação hídrica e as transmissíveis por pragas urbanas, bem como a dificuldade de acesso a serviços públicos essenciais (saúde, segurança, abastecimento e defesa).

Embora algumas dessas situações sejam identificadas às margens dos igarapés de Manaus por seus moradores, não necessariamente é válido afirmar que as pessoas estejam totalmente à mercê, já que elas próprias tratam de desenvolver estratégias diante das condições de vida dos espaços em que habitam. Com isso não se pretende fazer apologia à falta de serviços públicos ou riscos ambientais, mas sim, ampliar a visão sobre como os habitantes das áreas de risco qualificadas sobrevivem esses espaços.

Muito se tem falado sobre a importância de se adotar medidas que garantam o direito á saúde estabelecido pela CRFB, de 1988, chegando-se a cunhar expressões como melhoria das condições de vida ou melhoria da qualidade de vida dessas populações. Entende-se, porém, que é importante discutir o que se entende por qualidade de vida, pois é possível cair no risco de esvaziar de conteúdo este conceito ou, pior ainda, que seu uso liberado ao senso comum por trás de uma suposta naturalização do conceito acabe por atribuir-lhe os sentidos que os grupos dominantes oferecem ao termo.

\section{REFERÊNCIAS}

ABREU, Haroldo. Para além dos direitos: cidadania e hegemonia no mundo moderno. Rio de Janeiro: UFRJ, 2008.

ALEXY, Robert. Teoria dos Direitos Fundamentais. Tradução de Virgílio Afonso da Silva. São Paulo: Malheiros, 2011.

ANDRADE, Moacir. Manaus: Ruas, Fachadas e Varandas. Manaus: Humberto Calderaro, 1984.

ASENSI, Felipe Dutra. O direito à Saúde no Brasil. In: ASENSI, Felipe Dutra; PINHEIRO, Roseni (Orgs.). Direito Sanitário. Rio de Janeiro: Campus Jurídico, 2012. p. 02-26.

BARATA SOUZA, Leno José. A “Cidade Flutuante” de Manaus: rediscutindo conceitos. Aedos, Rio Grande do Sul, v. 3, n. 6, p. 149-165. 2010. 
BARROSO, Luís Roberto (Org.). O novo Direito Constitucional Brasileiro. Belo Horizonte: Fórum, 2013.

BITENCOURT NETO, Eurico. O direito ao mínimo para uma existência digna. Porto Alegre: Livraria do Advogado, 2010.

BITTAR, Eduardo C. B. O Direito na Pós-Modernidade. Rio de Janeiro: Forense Universitária, 2005

BRASIL. Constituição (1988). Constituição da República Federativa do Brasil. São Paulo: Saraiva, 2016.

Decreto $\mathrm{n}^{\circ}$ 591, de 6 de julho de 1992. Atos Internacionais. Pacto Internacional sobre Direitos Econômicos, Sociais e Culturais. Promulgação. Disponível em: http://www.planalto.gov.br/ccivil_03/decreto/1990-1994/d0591.htm. Acesso em fevereiro de 2019.

Secretaria de Direitos Humanos da Presidência da República. Direito à moradia adequada. Brasília: Coordenação Geral de Educação em SDH/PR, Direitos Humanos, Secretaria Nacional de Promoção e Defesa dos Direitos Humanos, 2013. Disponível em http://www.urbanismo.mppr.mp.br/arquivos/File/DH_moradia_final_internet.pdf.

CARDOSO, Adauto Lúcio. Política Habitacional: a descentralização perversa. Cadernos IPPUR, v. 1, n.1, jan./abr. 1986.

CARVALHO, Luiz. Amazônia: espectros de globalização. Manaus: Editora UFAM, 2009. 192p.

CONAMA - Conselho Nacional do Meio Ambiente - órgão consultivo e deliberativo do Sistema Nacional do Meio Ambiente-SISNAMA, que dispõe sobre a Política Nacional do Meio Ambiente. Disponível em: http:/ /www.mma.gov.br/port/conama. Acesso em janeiro 2019.

CORREA, Roberto Lobato. Região e organização espacial. São Paulo: Ática S.A, 2007.

DALLARI, Dalmo de Abreu. Direitos Humanos e Cidadania. São Paulo: Moderna, 2002.

DUDH - Declaração Universal dos Direitos Humanos. 1948. Disponível em: https:/ www.ohchr.org/ EN/UDHR/Documents/UDHR_Translations/por.pdf.

FLEURY, Sonia: AMARANTE, Paulo; BAHIA, Lígia (Orgs.). Saúde em debate: fundamentos da reforma sanitária. Rio de Janeiro: Cebes, 2007. v. 1, p. 144-148.

GAZOLA, Patrícia Marques. Concretização do direito à moradia digna: teoria e prática. Belo Horizonte: Fórum, 2008.

MESQUITA, Otoni Moreira de. Manaus - história e arquitetura (1852-1910). 3. ed. rev. Manaus: Valer; Prefeitura de Manaus; UNINORTE, 2006.

MONTEIRO, Mário Ypiranga. Fundação de Manaus. 4. ed. aum. Manaus: Metro Cúbico, 1994.

NOLASCO, Loreci Gottschalk. Direito Fundamental à Moradia. São Paulo: Editora Pillares, 2008.

NUNES, Benedito; HATOUM, Milton. Crônica de duas cidades: Belém e Manaus. Belém: SECULT/PA, 2005.

OLIVEIRA, Francisco; SCHOR, Tatiana. Manaus, a paisagem em movimento: os impactos de intervenção urbana do Programa Social e Ambiental dos Igarapés. Relatório de Pesquisa. Manaus: UFAM; Brasília, DF: CNPq, 2008.

OMS - Organização Mundial da Saúde. Administração da OMS. Disponível em: . Acesso em: 17. Jan. 2019

PINTO, Lucio Flávio. O Amazonas é Manaus. Jornal Pessoal, Belém, v. 5, n. 84, p. 3, fev. 1992.

SARLET, Ingo Wolfgang. Dignidade da Pessoa Humana e Direitos Fundamentais na Constituição Federal de 1988. Porto Alegre: Livraria do Advogado, 2001.

SAULE JUNIOR, Nelson. A proteção jurídica da moradia nos assentamentos irregulares. Porto Alegre: Sérgio Antônio Fabris Editor, 2004.

SCLIAR, Moacyr. História do conceito de saúde. Physis [online]. 2007, vol. 17, n. 1, pp. 29-41.

SEGRE, Marco; FERRAZ, Flávio Carvalho. O conceito de saúde. Rev. Saúde Pública, São Paulo, v. 31, n. 5, p. 538-542, outubro de 1997. 